\title{
Learning styles and their relation to teaching styles
}

\author{
Hawkar Akram Awla \\ The University of Koya, Faculty of Humanities \& Social Sciences, English Department, Koya, Iraq
}

Email address:

hawkar.akram@koyauniversity.org

\section{To cite this article:}

Hawkar Akram Awla. Learning Styles and Their Relation to Teaching Styles. International Journal of Language and Linguistics. Vol. 2, No. 3, 2014, pp. 241-245. doi: 10.11648/j.ijl1.20140203.23

\begin{abstract}
It is widely believed that understanding students' learning style and preferences can benefit both students and teachers. As students learn in various ways, it appears impossible to change the learning style of each student in the classroom. Instead, teachers might modify their teaching style so as to be more consistent with their students learning style. The purpose of this paper is three-fold.: first, to define and classify the concept of learning styles; second, to give an account of the significance of identifying and understanding learners' learning styles; third, to argue that students will have better achievements, if their teachers' styles or the way they receive instruction matches their learning style. Moreover, it is suggested that teachers should take a balanced approach to teaching styles so that they can cope with various learning styles. The study takes a theoretical approach to review relevant literature on the topic and present various view points on matching and/or mismatching leaning styles with teaching styles.
\end{abstract}

Keywords: Learning Styles, Teaching Styles, Matching Learning Styles and Teaching Styles

\section{Introduction}

There is no doubt that learners and teachers are different in various ways. Gaining knowledge on students' learning styles can be very helpful for both teachers and learners. Involving learners in the active process of learning requires identifying and understanding learners learning styles and teachers teaching styles. The two can either be matched or mismatched. It is vital to study the relationship between them. Many studies have been conducted on match and mismatch of learning styles and teaching styles (e.g.Naimie et al 2010; Massa and Mayer 2006; Tuan 2011). Most of them refer to matching the two as having a positive impact on the students' performance and indicate the opposite for mismatching. However, mismatches sometimes maybe useful especially with low level students (Peacock 2001). The purpose of this study is to present some arguments on this issue.

\section{Definition of Learning Styles}

Different terms have been used in literature such as learning style, cognitive style, sensory preference, and personality types. Some of these terms, in some instances, have been used interchangeably, while in other occasions they have been differentiated (Cassidy, 2004). Learning style are defined as "the complex manner in which, and conditions under which, learners most effectively perceive, process, store, and recall what they are attempting to learn" (James and Gardner, 1995: 20), while cognitive styles are defined as "an individuals' natural, habitual, and preferred way (s) of absorbing, processing and retaining new information and skills" (Reid, 1995: viii). Mortimore (2003) makes a distinction between learning styles and cognitive styles. He indicates that learning styles are seen more in terms of the strategies that learners use to deal with learning, and are considered to be less stable. On the other hand, cognitive styles are relatively stable. Thus, learning styles, as opposed to learner preferences, can be stretched with the passage of time. It is to be noted that the distinction between cognitive and learning style is not crystal clear as some authors employ cognitive style as a more general term that includes learning styles (Williamson and Watson, 2006).

\section{Classification of Learning Styles}

Broadly speaking, learning styles can be categorized into three main types: cognitive, personality (psychology), and sensory. Cognitive encompasses analytical/ global, fielddependent/field independent, impulsive/ reflective learning styles, Kolb's model of learning styles and Ehrman and Leavers' construct. Personality learning styles include extroverted/introverted, random-intuitive/concrete sequential, and closure-oriented/ open oriented. Sensory 
learning styles are divided into three sub-types: visual, tactile/kinesthetic and auditory (Dornyei, 2005; Oxford, 2001). In the following section, only those learning styles are explained which will be covered in the research part.

Visual versus verbal

Visual learners prefer to think in pictures and obtain information through visual means such as diagrams and videos. In contrast verbal learners gain more information through verbal explanations (either spoken or written) (Ldpride,n.d; Felder, 1993).

\section{Auditory learners}

Auditory learners gain information through aural channels such as verbal discussions and listening to others speech. These learners understand meaning by concentrating on the pitch, tone and speed of voice. They benefit from reading text out loud and they may not make use of written information (Ldpride,n.d.).

Kinesthetic or tactile learners: they like movement and work with touchable objects. They enjoy regular breaks and move around the room (Oxford, 2001).

Intuitive (random) versus Sensing (sequential)

Intuitive learners prefer information that originates from their imagination, reflection and internal memory. They think in futuristic, no-sequential and large-scale ways and enjoy creating new theories and possibilities. Conversely, sensing learners prefer information that arises from senses. They think about here and now, and prefer facts to theories. They would like to be guided and instructed by teachers (Felder, 1993; Oxford, 2001).

\section{Global versus analytic}

Global learners concentrate on the big picture and follow their instincts or guess the main idea of a text. They like short answers rather than long explanations. On the other hand, analytic learners focus on logical analysis and thinking to tackle problems. They break ideas apart and tend to place more emphasis on grammar rules (Dornyei, 2005).

\section{Active versus Reflective}

Active learners enjoy doing tasks directly by applying and discussing them with others, while reflective learners understand and remember information best by reflecting on it in advance. Active learners prefer to work in groups, while reflective learners enjoy working alone or in pairs (Felder, 1993)

Individual versus group preferences

Individual learners prefer to work and learn independently on their own. On the other hand, learners with a group preference like to study and learn in groups (Dornyei, 2005).

\section{The Importance of Identifying and Understanding Learning Styles}

Learning styles play a significant role in the lives of learners. When students recognize their own learning style, they will be able to integrate it into their learning process.
As a result, learning process will be easier, faster, and more successful. Another benefit of identifying learners' style is that it assists them in solving problems more effectively. The more successful learners at dealing with their problems, the better they will control their own lives (Biggs, 2001).

Furthermore, understanding learning style helps learners in learning how to learn. Thereby, learners become more autonomous and accountable for their own learning. Consequently, learners' confidence will increase and teachers control over learners will lessen. At this point, learners become the center of the learning process and control their learning while teachers act as facilitators (Gilakjani and Ahmadi, 2011). Another advantage of understanding learning styles is that it helps teachers to design lesson plans to match their students' styles. Matching is especially important when dealing with new or poor learners as they easily become frustrated at this stage of learning. In other occasions, mismatching might be convenient as to help learners experience new methods of learning and accommodate different ways of thinking and reflect on their own styles. However, mismatching should be treated with cautious as it may lead to learners' dropouts (Tuan, 2011).

In addition, (Ldpride,n.d.) suggests three advantages of identifying learning styles: Academic, personal, and professional advantages. Academic benefits include enhancing students learning ability, triumph over all educational stages, finding out how to study in an ideal way and gain good grades on tests and exams, controlling classroom limitations, alleviating frustration and levels of stress, and broadening your existing repertoire of learning strategies. Personal merits include increasing students' selfesteem and self-confidence, learning how to best optimize learners' brain, knowing students strong and weak points, learning how to make learning more enjoyable, increasing motivation for learning, and learning how to strengthen students' innate abilities and skills. Professional virtues encompass being informed of professional topics, gaining an advantage over competition, being effective in team management, developing students' sales kills, and surging power of earning.

\section{Matching Learning Styles to Teaching Styles}

It is assumed that learners learn better, if their learning styles match the format of their instruction. For example, a visual learner may learn better, when information is presented to him/ her visually. This approach is termed "learning hypothesis" or, in its recent version, "meshing" or "matching hypothesis" (Pasher et al, 2009:108). Conversely, a mismatch may leave negative impacts on the learners. In the following sections some discussions will be presented based on reviewing relevant literature to learning hypothesis or matching hypothesis.

Spoon and Schell (1998) conducted a study at a public 
coeducational technical institute in Georgia. One objective was to make a comparison between achievement levels of participants who received instruction that was matched and mismatched with their perceived learning style. 12 teachers and 189 students participated in the study. Permission to use the Principles of Adult Learning Scale was used to measure the elements included in learning and teaching styles. The data were collected by administering the PALS instrument among the students. The teacher data were gathered by meeting with them and asking them to complete a demographic survey. At the outset of the study, the students received a learning style inventory, while teachers were given a teaching style inventory. Based on completion of their inventories, teachers and students were divided into congruent and incongruent groups. Statistical analysis indicated that there was not a significant difference between the two groups. Thus, the study failed to support learning hypothesis.

Recently, in a well-structured study, Massa and Mayer (2006) in three experiments examined 52 college students in the Psychology Department at California University. The researchers designed a computer based class on electronics. Two distinct kinds of help screens were tailored to provide visual and verbal learners with illustrations and printed texts, respectively. Verbalizers and visualizers were separated from each other by using a number of measuring instruments assessing their learning preferences, cognitive style, and spatial ability. The study aimed to find out whether visualizers learn better from combined instruction that provides help screens utilizing pictures or verbalizers learn better from combined instruction that provides help screens employing words. In brief, the results revealed that there was no tendency for a better achievement for those who were offered help screens consistent with their style preferences. Thus, the result was not supportive of providing different teaching methods for visual and verbal learners.

In a medical- educational setting, Cook et al (2009) studied a population of 123 intern doctors and delivered web-based ambulatory modules. They aimed at testing the hypothesis that learners with a sensory style of learning would perform better when provided with instruction in which a problem was first introduced before the content information utilized to tackle the problem. On the other hand, learners with an intuitive style of learning would perform better in the opposite way. Participants were asked to complete two modules employing the two mentioned formats of instruction. At the end of each module, a test was used to determine the knowledge and the main outcome. Over time and in the middle of the two formats, a comparison was made between the two test scores. Statistical analysis of the results showed no significant relation between the two instruction formats. Thus, the study was not successful in validating the hypothesis.

In a similar study, Constantinidou and Baker (2002) examined the impact of presentation modalities on the oral learning of 52 younger and older adults (an equal proportion from both genders). A laboratory task was used to find out if the learners' preferences in the uptake of information predicted their ability to comprehend and save information in various modalities. A Visualizer-Verbalizer Questionnaire (VVQ) was used to examine the relation between the scores of the adults and their performance in verbal free-recall on a task that showed words via visual modality, auditory modality or both. The VVQ contained a number of questions which required the learners to indicate their preferences via oral versus visual methods. The results indicated that there was not a strong relation between the VVQ scores and the performance of free-recall levels for various input modalities. It was also found that the visual presentation yielded better free-recall in comparison with the oral presentations. Thus, the researchers found no significant relation between the visual and oral presentation of the items.

These four studies did not provide support for the learning or meshing hypothesis. However, these negative results cannot be deemed as a complete refutation of the hypothesis. Sternberg et al (1999) undertook a study to determine whether learners whose style matches the instruction they receive perform better than their mismatched counterparts do. A group of 324 proficient and gifted high school students were the study sample. A selection procedure was made on the basis of the students' performance on the Sternberg Triarchic Abilities (STA). The test determined the score of each student's creative, analytical and practical ability. Based on the test scores, the researchers selected a group of 112 students who had a higher rating for one of the tree mentioned abilities than the other two. Based on their skilled areas, the students were divided into three groups: high creative, high analytical and high practical. Another group of 87 students were divided into two other sub-groups, and the rest of the subjects were not included in the study. The participant students then registered for a psychology course at the University of Yale, and each subject was arbitrary chosen to participate in class meetings that focused on creative, analytical and practical instruction or memory instruction. An assessment of the course performance was made by using various measures. Finally, the researchers analyzed the data and made a comparison between the performance of matched subjects and the mismatched ones. The results showed that matched subjects outperformed their mismatched peers on two of the three types of assessments.

Peacock (2001) carried out a study to test Reid's (1987) hypothesis that incongruence between learning and teaching styles leads to learning failure, demotivation, and frustration. Reid's questionnaire, tests and interviews were used for the data collection utilizing 46 EFL teachers and 206 EFL students at a university in Hong Kong. It was discovered that the teachers preferred auditory, kinesthetic and group styles and disliked individual and tactile styles while the students preferred auditory and kinesthetic styles and disliked group and individual styles. Thus, incongruence was noticed concerning auditory and group styles. The interview results indicated that $70 \%$ of the learners were discouraged by incongruence between 
learning and teaching styles; $76 \%$ stated that it had a negative impact on their learning; and $81 \%$ of the teachers were content with Reid's' hypothesis. In conclusion, Peacock proposed a balanced style for teachers to adjust to various learning styles.

In a recent study, Naimie et al (2010) investigated the influence of matching or mismatching learning and teaching styles on the achievement of learners. 310 students were randomly selected from the faculty of foreign languages at the University of Azad in Iran. The Felder and Solomon's (1997) Learning Style Index (LSI) plus observations, survey questionnaire and interviews were employed for the data collection. The LSI included four dimensions: Active/ Reflective, Sensing/Intuition, Visual/Verbal, Global/ Sequential. A comparison was made between learning style preferences and achievement scores of matched-learning-teaching styles with mismatched learning-teaching styles across all of these four dimensions. The results of the study revealed that Active, Sensing, Visual, and Global, respectively, were the main learning styles of the students. To find out the influence of match and mismatch of learning and teaching styles, the students were classified into five groups on a rating scale (0-4), 0 indicating a complete mismatch and 4 indicating a perfect match. The analysis of the results showed that matching learning and teaching styles positively influenced the students' achievement.

In a similar study, Naimie et al (2010) attempted to identify: first, the extent to which the accommodation of learning style preferences is addressed by EFL classroom teachers, second, the effect of match and mismatch between learning and teaching styles on the attainment of the learners. The sample of the study was 100 English major undergraduates and two experienced teachers at a university in Iran. Interview and observation were used as instruments for the data collection. A survey questionnaire was also used to identify the teachers' and students' learning styles. The results indicated that the dominant learning style were active, sensing, and global respectively, while the teachers frequent learning styles were active, sensing, visual, and an equal distribution of global and sequential at the last dimension. The authors concluded that the students showed a positive attitude and higher attainment when their teachers accommodated their needs and preferences.

More recently, Tuan (2011) conducted a study to identify how teachers understand their students learning preferences as well as the extent of mismatch between students' and teachers' styles which has led to students' low performance and frustration. The sample was 12 teachers and 168 students from eight EFL classes in Vietnam. A questionnaire survey consisted of 44 closeended questions was distributed among the students of low upper intermediate and intermediate classes. Studentteacher style matching was measured by class observation. The results showed that the Vietnamese learners were more visual than verbal, more intuitive than sensing, more sequential than global, and more active than reflective. There was also some mismatch between the students' learning styles and the teachers' teaching styles. After matching learning styles, the Felder's (1993) and the Kolb's (1984) multiple teaching strategies were applied to stretch the learners' style. While the teachers' role was to guide students to particular learning styles, they had to familiarize themselves with new teaching styles. Despite the failure of style stretching by some students and teachers, the study confirmed the advantages of style stretching and matching.

In my experience, as a learner I have always gained higher scores in those lessons where my learning style has been consistent with my teacher's teaching style. This congruence has helped me to predict the teacher's expectations for the required answers. I am an analytic learner and I prefer analyzing and thinking in exams. Therefore, I have to consider the teachers style before answering the questions. However, I have, sometimes, found a mismatch between my learning style and my teacher's teaching style useful as it helps me to bring and adopt more styles into my learning style repertoire.

\section{Conclusion}

In the light of what has been discussed so for, it can be concluded that learning styles play an important role in the lives of learners. When students recognize their own learning style, they will be able to integrate it into their learning process. As a result, learning process will be enjoyable, faster, and more effective. Moreover, teachers should try to adjust their teaching styles so that they match their students' learning styles. However, a mismatch might sometimes be important especially with low level students as they feel disappointed at the early stages of learning but it should be done with caution. In addition, Peacock (2001:15) proposes that "teachers should strive for a balanced teaching style that does not excessively favor any one learning style - rather that tries to accommodate multiple learning styles".

\section{References}

[1] Biggs.J. (2001) Enhancing Learning: A Matter of Style or Approach? In R.J. Sternberg, L.F

[2] Zhang,( Eds), Perspectives on Thinking, Learning and Cognitive Styles. Mahwah, NJ: [3] Lawrence Erlbaum Associates, Publishers.

[3] Cassidy, S. (2004) Learning styles: An overview of theories, models, and measures. Educational Psychology, 24 (4), 419441.

[4] Cohen, A.D. and Weaver, S.J. (2005) Styles and strategiesbased instruction: a teachers' guide Minneapolis, MN: Center for Advanced Research on Language Acquisition, University of Minnesota. Retrived on April,20, 2012, from http://elechina.super-red.es/cohen-weaver.pdf. 
[5] Constantinidou, F., \& Baker, S. (2002) Stimulus modality and verbal learning performance in normal aging. Brain and Language, 82, 296-311.

[6] Cook, D.A., Thompson, W.G., Thomas, K.G., \& Thomas, M.R. (2009) Lack of interaction between sensing-intuitive learning styles and problem-first versus information-first instruction: A randomized crossover trial. Advances in Health Science Education, 14, 79- 90.

[7] Dörnyei, Z. (2005). The psychology of the language learner: Individual differences in second language acquisition. Mahwah, NJ: Lawrence Erlbaum. Associates, Publishers.

[8] Felder. R. (1993). Reaching the Second Tier: Learning and Teaching Styles in College Science Education. J.College Science Teaching, 23(5), 286-290.

[9] Gilakjani A.P, Ahmadi, S.M. (2011). Paper title: The Effect of Visual, Auditory, and Kinesthetic Learning Styles on Language Teaching. International Conference on Social Science and Humanity, 5, 496-472

[10] James, W. B., and Gardner, D. L. (1995) Learning Styles: Implications for Distance Learning. New Directions for Adult and Continuing Education no. 67, 19-32.

[11] LdPride.(n.d.),What are learning styles? Retrieved on March, 29, 2012 from http://www.ldpride.net/learningstyles.MI.htm.

[12] Massa, L.J., \& Mayer, R.E. (2006) Testing the ATI hypothesis: Should multimedia instruction accommodate verbalizer-visualizer cognitive style? Learning and Individual Differences, 16, 321-336.

[13] Mortimore, T. (2003) Dyslexia and Learning Style. A Practitioner's Handbook. London: Whurr Publishers Ltd.

[14] Naimie, Z., Siraj, S., Piaw, C. Y., Shagholi, R., Abuzaid, R.A. (2010) Do you think your match is made in heaven? Teaching styles/ learning styles match and mismatch revisited. Procedia Social Behavioral Sciences, 2, 349-353.
[15] Naimie, Z., Siraj, S., Shagholi, R., Abuzaid, R.A. (2010) Did you cook your lesson based on right recipe? (Accommodating the Students Preferences in Class) Social Behavioral Sciences, 2, 383-387.

[16] Oxford, R. (2001) Language learning styles and strategies. In. M. Celce-Murcid, Ed.Teaching English as a second or foreign language (3 ed.). US A: Heinle \& Heinle.

[17] Pashler, H., McDaniel, M., Rohrer, D., \& Bjork, R. (2009) Learning styles: Concepts and evidence. Psychological Science in the Public Interest, 9(3), 105-119.

[18] Peacock, M. (2001) Match or mismatch? Learning styles and teaching styles in EFL. International Journal of Applied Linguistics, 11(1), 1-20.

[19] Reid, J.M. (1987) The learning style preferences of ESL students. TESOL Quarterly,21(1), 87-111.

[20] Reid, J.M. (1995) Learning Styles in the ESL/EFL Classroom. Boston: Heinle \& Heinle Publishers.

[21] Felder, R. M., \& Soloman, B. A. (1997) Index of Learning Styles Questionnaire. Retrieved on June, 9, 2006 from http://www.engr.ncsu.edu/learningstyles/ilsweb.html

[22] Spoon.J. C, Schell, J .W. (1998) Aligning Student Learning Styles with Instructor Teaching. Journal of Industrial Teacher Education, 35(2), 41-56

[23] Sternberg, R.J., Grigorenko, E.L., Ferrari, M., \& Clinkenbeard, P.(1999) A triarchic analysis of an aptitudetreatment interaction. European Journal of Psychological Assessment, 15, 1-11.

[24] Tuan.L.T. (2011) Matching and Stretching Learners' Learning Styles. Journal of Language Teaching and Research, 2(2), 285-294.

[25] Williamson, MF. \& Watson, R. (2006) Learning Styles Research: Understanding How Teaching Should Be Impacted by the Way Learners Learn .Christian Education Journal, 3(1), 27-43. 